\title{
Equipes autogerenciáveis: Conquistas e desafios
}

\author{
Self-managing teams: Achievements and challenges \\ Equipos autogestionadores: Logros y retos
}

Recebido: 24/06/2021 | Revisado: 01/07/2021 | Aceito: 04/07/2021 | Publicado: 07/07/2021

\author{
Virginia Tomaz Machado \\ ORCID: https://orcid.org/0000-0002-3698-5468 \\ Faculdade Santa Maria, Brasil \\ E-mail: vtmachado@hotmail.com \\ Eduardo Ferreira Silva \\ ORCID: https://orcid.org/0000-0003-0001-7526 \\ Faculdade Santa Maria, Brasil \\ E-mail: duduff33@gmail.com \\ Rosangela Pereira de Oliveira \\ ORCID: https://orcid.org/0000-0003-3615-6974 \\ Faculdade Santa Maria, Brasil \\ E-mail: rosangelamat19@hotmail.com \\ Fernando Antônio Portela da Cunha \\ ORCID: https://orcid.org/0000-0002-0022-0068 \\ Universidade Federal de Campina Grande, Brasil \\ E-mail: fportela.ufcg@gmail.com \\ João Paulo Freitas de Oliveira \\ ORCID: https://orcid.org/0000-000203998-5236 \\ Faculdade Santa Maria, Brasil \\ E-mail: joaopaulofreitas@gmail.com \\ Andreia Braga de Oliveira \\ ORCID: https://orcid.org/0000-0002-6251-4256 \\ Faculdade Santa Maria, Brasil \\ E-mail: andreiabragapb@gmail.com \\ Luiz Carlos Machado de Sousa Filho \\ ORCID: https://orcid.org/0000-0002-0914-3820 \\ Seminário Arquidiocesano da Paraíba, Brasil \\ E-mail: peluizcarlos@hotmail.com \\ Josias da Silva Fonseca \\ ORCID: https://orcid.org/0000-0003-4627-5694 \\ Faculdade Santa Maria, Brasil \\ E-mail: Josiasmiranda1958@hotmail.com.br
}

\begin{abstract}
Resumo
Com a competitividade existente no mercado, a busca das organizações pela eficiência requer processos de excelência, que primem pela qualidade na atuação empresarial. Com isto, as empresas buscam, incansavelmente, pelo capital intelectual, que possa ser sujeito diferenciador neste cenário. Diante disto, o trabalho visa mostrar conquistas e desafios que as equipes autogerenciáveis trazem para as organizações, descrevendo o ambiente propício para o desenvolvimento das equipes autogerenciáveis. Tratou-se de um estudo de caso, descritivo e exploratório. Quanto à abordagem, potencializou-se a partir do método quantitativo e qualitativo, no qual utilizou-se na coleta de dados um questionário semiestruturado, aplicado a uma empresa de consultoria na área da Gestão de Pessoas (GP), que vem ao longo de vinte anos trabalhando para inserir colaboradores de alto desempenho nas empresas do mercado, como em formar em seu quadro laboral equipes autogerenciáveis. O questionário foi aplicado no setor de GP, este composto de oito colaboradores. Como resultado demonstrou a importância de ter equipes autônomas dentro das empresas, porém imerso a diversas dificuldades no enfrentamento das atividades laborais bem como: falta do empoderamento dos membros da equipe; insegurança no processo decisório; dificuldade da gerência na delegação nas decisões. Contrapondo-se aos diversos desafios enfrentados, têm-se as inúmeras conquistas da equipe que sobressaem às perspectivas dos objetivos previamente traçados pela empresa, no alcance do crescimento e desenvolvimento organizacional.
\end{abstract}

Palavras-chave: Equipes autogerenciáveis; Conquistas e desafios; Empowerment; Formação de células eficientes.

\section{Abstract}

With the existing competitiveness in the market, the search of organizations for efficiency requires processes of excellence, which excel in quality in business performance. With this, companies tirelessly seek intellectual capital, which can be a differentiating subject in this scenario. In view of this, the work aims to show achievements and challenges that self-managing teams bring to organizations, describing the environment conducive to the development 
of self-managing teams. This was a descriptive and exploratory case study. As for the approach, it was enhanced from the quantitative and qualitative method, in which a semi-structured questionnaire was used in data collection, applied to a consulting company in People Management (GP), which has been working for twenty years to insert highperformance employees in the companies of the market, such as forming self-manageable teams in their workforce. The questionnaire was applied in the GP sector, which consisted of eight employees. As a result, it demonstrated the importance of having autonomous teams within the companies but immersed in several difficulties in coping with work activities as well as: lack of empowerment of team members; insecurity in the decision-making process; difficulty of management in delegation in decisions. In contrast to the various challenges faced, there are the numerous achievements of the team that outlast the perspectives of the objectives previously outlined by the company, in achieving organizational growth and development.

Keywords: Self-managing teams; Achievements and challenges; Empowerment; Efficient cell formation.

\section{Resumen}

Con la competitividad existente en el mercado, la búsqueda de organizaciones para la eficiencia requiere procesos de excelencia, que sobresalen en calidad en el desempeño empresarial. Con ello, las empresas buscan incansablemente capital intelectual, que puede ser un tema diferenciador en este escenario. Ante esto, el trabajo tiene como objetivo mostrar los logros y desafíos que los equipos de autogestión aportan a las organizaciones, describiendo el entorno propicio para el desarrollo de equipos autogestionadores. Se trata de un estudio de caso descriptivo y exploratorio. En cuanto al enfoque, se mejoró a partir del método cuantitativo y cualitativo, en el que se utilizó un cuestionario semiestructurado en la recogida de datos, aplicado a una empresa consultora en el área de Gestión de Personas (GP), que lleva veinte años trabajando para insertar empleados de alto rendimiento en las empresas del mercado, como formar equipos autogestionables en su plantilla. El cuestionario se aplicó en el sector de GP, que constaba de ocho empleados. Como resultado, demostró la importancia de contar con equipos autónomos dentro de las empresas, pero inmersos en varias dificultades para hacer frente a las actividades laborales, así como: falta de empoderamiento de los miembros del equipo; la inseguridad en el proceso de adopción de decisiones; dificultad de gestión en la delegación en las decisiones. En contraste con los diversos desafíos enfrentados, existen los numerosos logros del equipo que sobreviven a las perspectivas de los objetivos previamente trazados por la empresa, en el logro del crecimiento y desarrollo organizacional.

Palabras clave: Equipos autogestionar; Logros y desafíos; Empoderamiento; Formación celular eficiente.

\section{Introdução}

No atual cenário, com organizações cada vez mais competitivas, na busca da melhoria contínua dos processos, com produção elevada e de qualidade, utilizando o mínimo de recursos, o fato de ter um quadro de colaboradores de excelência, faz toda a diferença neste cenário. Com isto, as empresas buscam incessantemente métodos e ferramentas para aprimorar seus colaboradores, transformando-os em equipes compostas de capital intelectual, autogestada.

Nas últimas três décadas, estudos mostram uma nova alternativa para o gerenciamento de equipes, na perspectiva do melhor desempenho da organização na tomada de decisões no mundo empresarial, em contrapartida ao método tradicional de gerenciamento. O novo modelo propõe a construção de equipes com o gerenciamento diferenciado do modelo tradicional, no qual a decisão não é centralizada, mas sim construída e compartilhada pela equipe (Cardozo, 2012).

Ainda conforme o autor supracitado, na abordagem tradicional, a liderança é uma função estritamente centralizada, na qual a autonomia individual se sobressai, em contrapartida à autonomia concedida para a equipe. Por outro lado, no novo modelo gerencial as equipes assumem responsabilidades de serem autogerenciáveis de forma compartilhada, observando e acompanhando seus próprios passos em execução, bem como, a análise e avaliação dos resultados.

Diante disto, sabe-se que o centro das atividades de execução dos processos passa a ser o colaborador. As empresas de sucesso são aquelas que têm seu olhar para o colaborador e um discurso inovador na descentralização das atividades, compartilhando-as com suas equipes. Em 1918, Mary Parker Follett já pontuava que as organizações se atentassem mais para o capital humano disponível e em como aproveitar melhor seu potencial (Robbins, 2000).

Entender sobre TAG, EMPOWERMENT, que significa "autoridade" para agir e executar mudanças no trabalho, ou na forma de como este trabalho é desempenhado (Slack et al., 1997), traz uma roupagem de liderança diferenciada para as organizações, uma vez que essas duas palavras vêm sendo discutidas com frequência nas organizações desde os meados dos 
anos 60, e induz a uma forma de gerenciamento que surge para substituir os modelos anteriormente implantados por Frederick Taylor, no qual dava ênfase às tarefas, e por Jules Henri Fayol, que dava ênfase às estruturas.

Para tanto, esta nova forma de gerenciamento dos colaboradores exige o encorajamento e estímulo dos mesmos na solução de problemas e conflitos, como também em imaginar e propor novas ideias e soluções para melhor executar as tarefas, com isto, definem-se equipes autogerenciáveis: que são grupos de pessoas executando trabalhos de forma independente, porém de estratégia grupal, sem interferência de um chefe, equipes tomando decisões e se responsabilizando (Robbins, 2005).

Já segundo Goodman e Hudson (1988), o autogerenciamento propõe que a equipe de trabalho seja composta por indivíduos interdependentes, que podem se autorregular e ter autonomia para tomar decisões sem supervisão direta.

Equipes autogerenciáveis produzem com inovação e criatividade além do comum ou esperado, porque a equipe tem liberdade de atuação e consegue enxergar o processo de trabalho por completo (Hitchcock \& Willard, 1995).

Conforme (Gama, et al., 2016), que pontua que os gestores na atualidade têm vislumbrado a necessidade de gerir os colaboradores de forma diferente, procurando desenvolver o trabalho em equipe, na colaboração e na inovação, promovendo o aprendizado permanente na disseminação do conhecimento, inspirando as iniciativas de cada um pelos valores compartilhados, entre outras. Diante disto, este trabalho mostra as conquistas e desafios das equipes autogerenciáveis para o crescimento da organização, descrevendo o ambiente propício para a atuação dessa equipe.

Neste contexto, pode-se entender que em uma organização, no qual existe um trabalho de equipe, o principal papel do gestor (líder) transpassa o papel de dar direções, isto é, dizer às pessoas o que fazer e como fazer, para apenas apresentar visões organizacionais. Uma vez que todos entendam e estejam comprometidos com essa visão, o líder não precisa assumir o papel de supervisor. Logo, neste cenário, o líder passa a assumir o papel de um facilitador de equipe. Com isto, faz-se necessário entender quais os desafios que as organizações enfrentam em formar equipes autogerenciáveis?

Diante disto, proporcionar mais liberdade de autonomia ao trabalhador é fundamental para as organizações em crescimento e que buscam agregar valores, já não há espaço para empresas burocráticas, no qual um vê o problema, comunica para o próximo e assim segue até chegar a quem detém a decisão, a informação ou a autoridade para resolver; é preciso ser mais dinâmico e flexível, isso é uma questão de permanência no mercado, principalmente quando as questões são urgentes e não detêm tanto tempo. Afinal, existe um custo do tempo perdido? A maioria das empresas não percebe esse tempo perdido e, quando enxerga, muitas vezes é tarde demais (Marras, 2011).

Não há dúvida de que o capital humano de uma organização tem um valor intelectual grande para o empreendimento, e isso vem sendo comprovado em estudos e pesquisas, mas a grande problemática é que muitas organizações não reconhecem e nem valorizam esse fator interno, essencial para o crescimento da organização.

As empresas devem desenvolver um contrato de parceria com seus colaboradores, no qual estes devem ter possibilidade de crescimento, atendimento às suas necessidades, trabalhos desafiadores e menos monótonos que os tirem da zona de conforto, e em troca agregue maior comprometimento e parceria com suas próprias metas na busca de obter resultados (Marras, 2011).

Do contrário, gera no colaborador a insatisfação que reflete no desempenho de todos em função do não reconhecimento na empresa, como também na relação com o cliente. Os empregados tratam os clientes da mesma proporção que se sentem tratados (Soto, 2008).

Não se sentirem satisfeitos e motivados, consequentemente não terão compromisso com a organização, e esse é também um dos grandes desafios enfrentados, uma vez que o colaborador não se sente "aceito" pela empresa, a sua produtividade reduz a níveis baixos, além disso, pode gerar problemas como alta rotatividade, ou seja, o famoso "demite e contrata", e também o absenteísmo e o custos de saúde com stress que advém (Kinicki \& Kreitner, 2006). 
Deste modo, a implementação de equipes autogeridas procura sanar tais necessidades, ao promover os colaboradores a funções enriquecidas, conhecimentos inovadores e autonomia, fazendo com que os mesmos se sintam valorizados, encorajados e motivados para obter resultados além do esperado para a organização e, quando isso acontece, a equipe se sente estimulada a enfrentar desafios maiores (Manz \& Sims, 1996).

Mas nem tudo é perfeito, podem surgir problemas com essas equipes devido ao trabalho ser descentralizado, certas atividades podem se desvincular em meio ao cronograma proposto, por isso, faz-se necessário um método em que todos os envolvidos estejam comprometidos e fiéis, a ausência de um gestor pode deixar a atividade executada sem liderança e, algumas vezes, sem conclusão. Não haver um controle rígido proporciona que nem sempre as atividades realizadas sejam vistas pelas demais áreas da organização (Júlio \& Neto, 2002).

Estes possíveis problemas elencados acima podem ocorrer na jornada da implantação das equipes autônomas, devendo ser analisados e acertados pelos próprios membros ou pelo gestor que está acompanhando o desenvolvimento dessas equipes.

São vários os benefícios de equipes autogerenciáveis que se pode elencar: proporcionar autonomia para os colaboradores; disseminar a capacidade de liderança dos indivíduos; flexibilidade na tomada de decisão; facilidade de perceber e se adequar às demandas; facilidade na interação com pessoas das mais diversas gerações, conhecimentos e áreas; agilidade no trabalho; quebra de ritmo e monotonia; rapidez nas ações e descentralização das tarefas, contudo, sem sobrecarregar ninguém (Júlio \& Neto, 2002).

Uma das vantagens que a equipes autônomas possui é o engajamento completo do colaborador com o trabalho e uma maior parceria com a organização, além do foco único para o objetivo estabelecido, o que gera sentimentos de valorização e pertencimento do trabalho, como se ele fosse o proprietário da empresa já que está inserido ativamente nas decisões (Robbins, 2005).

Para tanto exige um entendimento nas mais diversas vertentes da empresa na construção dos times de equipes autogerenciáveis e que, conforme Cassemiro, Cardoso \& Chaves, (2008), na perspectiva da organização, para que times de equipes autogerenciáveis tenham sucesso, com alto desempenho e baixo custo, é necessário atenção à diversidade dos fatores, bem como: o processo interno de trabalho; apoio da gestão; treinamento recebido pela equipe; formação do time; análise dos processos internos; características de cada componente da equipe; enfim, um conjunto de atributos necessários para que possam ser alcançados os objetivos organizacionais.

Segundo Gama, et al., (2016), tendo como perspectiva o colaborador, não há o que ser feito se os componentes dos times não possuem habilidades, capacidades e conhecimento que sejam relevantes para o objetivo central do projeto. Conhecimento, atitude e habilidade são características dos membros de equipes autogerenciáveis, isto é, competências que promovem impactos assertivos no que se propõem a fazer.

Para Meefe (2006), tendo como perspectiva a liderança é falsa a falácia de que, quanto mais poder tiver os membros de um time autogerenciável, menor poder terá o líder. Pelo contrário, quanto mais poder e influência tiver o líder sobre sua equipe melhor será a interação e busca pelos objetivos propostos. Na contemporaneidade, entende-se que os membros de equipes autogerenciáveis têm como função não só fazer sua parte, mas administrar como um todo, tendo em vista que cada qual possui autonomia suficiente para condução do empreendimento, no qual o líder fica com a função de nortear os objetivos propostos para o alcance (Kouzes \& Posner, 1997).

Nas exigências de um mercado cada vez mais competitivo, este novo modelo de equipes autogerenciáveis veio atender a necessidade de crescimento das organizações através das competências do seu quadro funcional (Charlwood \& Terry, 2007). Para estar inserido e conquistar este mercado, faz-se necessário inovação e flexibilidade aos contornos da mudança. 


\section{Metodologia}

Este trabalho constituiu em uma pesquisa realizada sobre as conquistas e desafios de uma equipe autogerenciável e suas aplicações. Demonstrou a importância de uma equipe com os resultados positivos para a empresa, contribuindo para sua existência no mercado e aumento no grau de competitividade da mesma em relação à concorrência.

Foi utilizada a pesquisa do tipo exploratória, descritivo, um estudo quanti qualitativo de abordagem de um estudo de caso. Desenvolve-se a partir do método quantitativo e qualitativo. Segundo Vergara (2008), este método mencionado diz respeito ao modo pelo qual seus dados foram coletados e submetidos ao estudo no modelo estatístico. Trabalhando de maneira conjunta entre quantidades, percentagens e análise ambiental do cenário estudado.

A pesquisa foi realizada em uma empresa de consultoria empresarial situada no município de Fortaleza - CE, localizada na região litorânea, cuja capital possui uma população estimada de 2.669 .342 de indivíduos. Conta ainda com uma grande área territorial de 312,40 $\mathrm{km}^{2}$ e densidade demográfica de 7.786,44 hab/ km², um PIB per capita de $\mathrm{R} \$ 23.436,66$, segundo o Instituto de Geografia e Estatística (2017).

A empresa pesquisada surgiu de um sonho idealizado por um grupo de três amigos que estavam cursando o Bacharelado em Administração, em encontros para estudo e um café, no qual, a partir de conversas, idealizaram novos rumos em comum para suas vidas profissionais.

No ano de conclusão do curso, os amigos decidiram colocar o sonho em prática e, com o apoio dos professores da instituição da graduação e do SEBRAE, começaram o negócio contando apenas com 01 colaborador de início.

Atualmente, o empreendimento conta com 99 colaboradores alocados nas mais diversas funções tais como, administrativo, financeiro, gestão de pessoas, acadêmico, secretaria, biblioteca, setor de planejamentos e projetos, entre outras, conforme apresentado na Tabela 1. A empresa, desde seu início, vem contribuindo na prestação dos serviços no setor de consultoria e educação para a melhoria e crescimento empresarial, com diferencial nos métodos e meios pelo qual se propõe a fazer, contribuindo de forma a engrandecer a atuação na região.

Tabela 1: Apresentação da empresa.

\begin{tabular}{lc}
\hline NOME FANTASIA & Empresa X \\
\hline $\mathbf{N}^{\circ}$ DE FUNCIONÁRIOS TOTAL & 99 \\
\hline $\mathbf{N}^{\circ}$ DE FUNCIONÁRIOS DO DEPARTAMENTO DE RH & 08 \\
\hline
\end{tabular}

Fonte: Dados da pesquisa (2020).

A empresa, além de ter a função de recolocação de colaboradores no mercado, trabalha também com cursos de capacitação, seja na área profissional, seja educacional (graduação e pós-graduação), a amostra foi dos componentes da área de Gestão de Pessoas (GP) com oito colaboradores, que se sentiram satisfeitos em dar uma parcela na contribuição para a realização desta pesquisa. Assim sendo, admite-se que foi abordado 100\% dos colaboradores do departamento de GP, no qual dois deles têm a função de selecionar e entrevistar, outros dois têm a função de analisar os recrutados, treinar e acompanhar o processo de desenvolvimento dos mesmos, dois têm a função de criar planos de carreira internos, um assistente de departamento e um o líder da equipe.

Os critérios utilizados para inclusão e participação foram ser celetista da empresa, estando atuando na atividade laboral com mais de 03 anos na empresa, e aceitando de livre e espontânea vontade em participar da pesquisa.

A coleta de dados só aconteceu após a aprovação do Comitê de Ética em Pesquisa, por intermédio da aplicação de um questionário do tipo semiestruturado, no qual consiste de uma adaptação feita pela Survey, e da observação sistemática. 
Compreendendo que toda pesquisa precisa estar baseada em princípios éticos, o presente estudo se fundamenta na resolução 510/16, do Conselho Nacional de Saúde, no qual se refere às questões éticas no tocante às pesquisas com seres humanos (Brasil, 2016). Com base nisso, o Comitê de Ética e Pesquisa (CEP) aprovou a pesquisa com o Parecer Consubstanciado do CEP $(\mathrm{CAAE})=35160420.9 .0000 .5180$, para tanto, os conteúdos coletados serão protegidos, envolvendo, absolutamente, o sigilo.

Segundo Yin (2001), a etapa da análise dos dados foi constituída como uma etapa importante na elaboração de um projeto, sendo iniciada após a aprovação do Comitê de Ética em Pesquisa, e é desempenhada com o intuito de responder os objetivos da pesquisa.

Ao término da coleta, esses dados foram reunidos e interpretados por meio do software Excel 2007. E seus respectivos resultados expostos em tabelas e gráficos para fácil visualização e entendimento dos mesmos, salientando as várias vertentes assumidas. Entretanto, filtrando as que de fato são relevantes para a pesquisa e interessados em sua resolução.

\section{Resultados e Discussão}

A primeira etapa da análise foi observada o perfil dos entrevistados e, em seguida, os benefícios e desafios de uma equipe autogerenciável, buscando alimentar as respostas com os objetivos descritos pelo estudo.

\section{Aspectos sóciodemográficos}

O setor de RH da empresa trabalha com seu quadro colaborativo de 50\% para os gêneros, de maioria jovem, isto reflete em uma maioria de solteiros, recebendo salários entre dois a quatro salários mínimos, todos com o ensino superior, e 50\% têm especialização na área de gestão de pessoas.

Percebe-se um baixo índice de rotatividade, já que 5 dos colaboradores estão há mais de 4 anos na organização e os demais entre 3 anos a 4 anos. Conforme Ferreira e Siqueira (2005), uma situação que bloqueia a rotatividade ou turnover é a satisfação do colaborador com a organização no qual atua, diante disto, parte do pressuposto de que os colaboradores se sentem realizados em fazer parte do quadro colaborativo. Quanto à função, 30\% ocupa a função de selecionar e recrutar, 30\% treinar e acompanhar o desempenho dos contratados, outros $30 \%$ na criação do programa de desenvolvimento e crescimento dos colaboradores, $5 \%$ como assistente do departamento e mais 5\% no cargo de liderança.

\section{Dados relativos à temática sobre equipe autogerenciáveis}

Ao ser argumentados sobre a percepção do ambiente laboral para um equipe autogerenciaveis, obtiveram os resultados conforme a Tabela 2 .

Tabela 2: Como enxergam o ambiente de trabalho para equipe auto gerenciáveis.

\begin{tabular}{lcc}
\hline Variáveis & $\begin{array}{c}\text { Referência } \\
\text { Absoluta }\end{array}$ & $\begin{array}{c}\text { Referência } \\
\text { Relativa }\end{array}$ \\
\hline Desafiador & 3 & $37,5 \%$ \\
\hline Dinâmico & 3 & $37,5 \%$ \\
\hline Motivador & 2 & $25 \%$ \\
\hline Total & 8 & $100 \%$ \\
\hline
\end{tabular}

Fonte: Dados da pesquisa (2020). 
Em relação como os colaboradores enxergam o ambiente de trabalho para equipes autogerenciáveis, no qual 37,5\% disseram que este ambiente precisa ser desafiador, outros 37,5\% dizem que o meio de atuação deve ser dinâmico, enquanto $25 \%$ relatam que necessita ser motivador.

Os fatores relacionados ao aprimoramento no ambiente de trabalho estão associados diretamente à QVT (Qualidade de Vida no Trabalho), a mesma busca ambiente que seja favorável para os colaboradores e seu desempenho dentro das organizações. A QVT pontua que os colaboradores devem ter suas habilidades desenvolvidas. Um meio de aprimorar a QVT é o conceito de enriquecimento nas atividades laborais desenvolvido por Frederick Herzberg, nele são acrescentados novos modelos de tarefa, que buscam promover um trabalho mais interessante, desafiador, dinâmico e motivador (Davis \& Newstrom, 1992).

Quando questionados sobre o que acham da necessidade de reuniões em grupo para planejar atividades, 87,5\% dos participantes responderam que se faz necessário que existam reuniões frequentes em grupo, enquanto $12,5 \%$ disse não achar necessário, resultados estes descritos na Tabela 3.

Tabela 3: Necessidade de reuniões de grupo.

\begin{tabular}{lcc}
\hline Variáveis & $\begin{array}{c}\text { Referência } \\
\text { Absoluta }\end{array}$ & $\begin{array}{c}\text { Referência } \\
\text { Relativa }\end{array}$ \\
\hline SIM & 7 & $87,5 \%$ \\
\hline NÃO & 1 & $12,5 \%$ \\
\hline \multirow{2}{*}{ Total } & $\mathbf{8}$ & $\mathbf{1 0 0 \%}$ \\
\hline
\end{tabular}

Fonte: Dados da pesquisa (2020).

Contudo, alguns problemas podem surgir com essas equipes diante do fato das atividades serem descentralizadas, algumas atividades podem se perder, sendo necessário um acompanhamento direto com discussões e debates, sendo as reuniões momento propício para tal, isto é, um modelo de gestão em que todos sejam comprometidos, pois a ausência de um único gestor pode afetar no trabalho (Júlio \& Neto, 2002).

$\mathrm{Na}$ tabela 04 , trata da relação do grau de importância de ter reuniões constantes para melhorar a performance da equipe autogerenciável, de novo $87,5 \%$ respondeu que é de suma importância, e outros 12,5\% que não acham necessário reuniões por tal motivo.

Tabela 4: A importância de reuniões para melhor performance da equipe.

\begin{tabular}{lcc}
\hline Variáveis & $\begin{array}{c}\text { Referência } \\
\text { Absoluta }\end{array}$ & $\begin{array}{c}\text { Referência } \\
\text { Relativa }\end{array}$ \\
\hline SIM & 7 & $87,5 \%$ \\
\hline NÃO & 1 & $12,5 \%$ \\
\hline Total & $\mathbf{8}$ & $\mathbf{1 0 0 \%}$ \\
\hline
\end{tabular}

Fonte: Dados da pesquisa (2020).

Conforme Robbins (2000) diz que uma equipe deve compartilhar missão e visão com a qual todos se comprometem, com uma convivência harmônica e comunicação clara, sentir-se pertencente à equipe, valorizar a diversidade, estimular a criatividade e capacidade de risco, ter a capacidade de se autoavaliar, possuir interdependência e harmonia na tomada mais 
propicia de decisões, fazer parte do contexto de uma liderança ativa, no qual as reuniões constituem um motor para o desempenho da equipe e o desenvolvimento da performance individual e da equipe, neste caso precisa do envolvimento de todos os processos organizacionais.

Para Robbins (2005), a comunicação imersa na equipe é vista como algo indispensável para o bom desempenho coletivo do grupo. Ou seja, a sinergia que deve existir entre todos os membros do grupo em um só pensamento, no caso missão e visão da organização, isto induz a liberdade de ação através da comunhão de ideias.

Ao serem questionados sobre a liberdade de trabalhar na célula sem a interferência da liderança, representada pela Tabela 5, pontuou-se que 62,5\% dos questionados replicaram que conseguem trabalhar melhor sem supervisão, 37,5\% responderam que se sentem mais seguros com a presença da liderança enquanto supervisão para trabalhar.

Tabela 5: Liberdade em excetuar as atividades sem interferência.

\begin{tabular}{lcc}
\hline Variáveis & $\begin{array}{c}\text { Referência } \\
\text { Absoluta }\end{array}$ & $\begin{array}{c}\text { Referência } \\
\text { Relativa }\end{array}$ \\
\hline SIM & 5 & $62,5 \%$ \\
\hline NÃO & 3 & $37,5 \%$ \\
\hline Total & $\mathbf{8}$ & $\mathbf{1 0 0 \%}$ \\
\hline
\end{tabular}

Fonte: Dados da pesquisa (2020).

Conforme Robbins (2005) diz que equipes autogerenciáveis são grupos de pessoas com poder de tomada de decisão, sem interferência de um chefe específico, tomando as próprias decisões em grupo, assumindo a total responsabilidade sobre as mesmas. Com isto, entende-se que esta equipe precisa de treinamentos para melhor entendimento da autonomia delegada pela liderança na formação de equipes autogerenciáveis.

Quando questionados sobre saberem da importância que cada colaborador tem para a empresa, a tabela 06 mostra que 87,5\% apontaram que têm consciência sobre a relevância que cada colaborador tem para a empresa, contrapondo-se a 12,5\% que relatou a não compreensão da importância da sua função para a organização.

Tabela 6: A importância de cada colaborador para a empresa.

\begin{tabular}{lcc}
\hline Variáveis & $\begin{array}{c}\text { Referência } \\
\text { Absoluta }\end{array}$ & $\begin{array}{c}\text { Referência } \\
\text { Relativa } \\
\text { Muito importante }\end{array}$ \\
\hline Não importante & 7 & $87,5 \%$ \\
\hline Total & 1 & $12,5 \%$ \\
\hline
\end{tabular}

Fonte: Dados da pesquisa (2020).

Para Chiavenato (2006), as empresas são necessariamente constituídas de pessoas, e que essas pessoas são possuidoras do capital intelectual, o capital necessário que a organização necessita, e este só será bem aplicado quando for valorizado e desenvolvido pela empresa. O retrato deste colaborador que contabiliza 12,5\% é algo que pode levar a equipe ao não alcance dos objetivos, devido o mesmo não acreditar no seu potencial e não entender o quanto a função que executa tem papel fundamental dentro de todo o processo organizacional.

Quanto à tomada de decisão no setor, $100 \%$ dos entrevistados responderam que todas as decisões do setor são realizadas sempre em grupo, envolto a uma gestão participativa, dados este presente na Tabela 7. 
Tabela 7: Tomadas de decisões realizadas na coletividade.

\begin{tabular}{lcc}
\hline Variáveis & $\begin{array}{c}\text { Referência } \\
\text { Absoluta }\end{array}$ & $\begin{array}{c}\text { Referência } \\
\text { Relativa }\end{array}$ \\
\hline SIM & 8 & $100 \%$ \\
\hline NÃO & - & - \\
\hline Total & $\mathbf{8}$ & $\mathbf{1 0 0 \%}$ \\
\hline
\end{tabular}

Fonte: Dados da pesquisa (2020).

O fato de equipes autogerenciáveis serem autônomas para tomar decisões faz com que os membros da equipe possam assumir a possibilidade de oferecer mais soluções para discutir e decidir em grupo, assumindo as consequências das decisões (Wellins, Byham \& Wilson, 1994).

Quando questionados sobre os treinamentos necessários para o desenvolvimento e empoderamento na tomada de decisões dentro do setor, 87,5\% afirmam que sim, contrapondo-se a 12,5\% que, apesar das capacitações e treinamentos oferecidos, não se sentem aptos o suficiente para tomar determinadas decisões quando necessário, por se sentir inseguros, conforme a tabela 08, já relacionando a Tabela 5, no qual 37,5\%, isto é, 3 colaboradores apontaram precisar de um líder para se sentir seguros, norteando os processos na tomada de decisão.

Tabela 8: Treinamentos para tomada de decisão.

\begin{tabular}{lcc}
\hline Variáveis & $\begin{array}{c}\text { Referência } \\
\text { Absoluta }\end{array}$ & $\begin{array}{c}\text { Referência } \\
\text { Relativa }\end{array}$ \\
\hline SIM & 7 & $87,5 \%$ \\
\hline NÃO & 1 & $12,5 \%$ \\
\hline Total & $\mathbf{8}$ & $\mathbf{1 0 0 \%}$ \\
\hline
\end{tabular}

Fonte: Dados da pesquisa (2020).

O papel da organização que busca a iniciativa de implantar uma equipe autogerenciável é de treinar os subordinados no intuito de que resolvam os problemas de execução da organização Martins, Ribeiro e Carvalho (2017). Para isto, o sucesso das equipes autônomas é o empowerment, empoderar os colaboradores. Porém, para que funcione, é necessário desmistificar tabus, de que o poder está com poucos. (Blanchard, Carlos \& Ranolph, 1996).

$\mathrm{Na}$ tabela 09 , relaciona às características de cada nas vantagens para a equipe autogerenciável do setor, $50 \%$ dos participantes pontuaram ser o dinamismo para lidar com as mais diversas situações, enquanto 37,5\% afirmam ser a produtividade, já outros $12,5 \%$ responderam que é a empatia, o fato de se colocarem no lugar do outro em momentos de conflito vividos pela equipe internamente e externamente. 
Tabela 9: Características individuais com relevância para a equipe.

\begin{tabular}{lcc}
\hline Variáveis & $\begin{array}{c}\text { Referência } \\
\text { Absoluta }\end{array}$ & $\begin{array}{c}\text { Referência } \\
\text { Relativa }\end{array}$ \\
\hline Dinamismo & 4 & $50 \%$ \\
\hline Produtividade & 3 & $37,5 \%$ \\
\hline Motivador & 1 & $12,5 \%$ \\
\hline Total & 8 & $100 \%$ \\
\hline
\end{tabular}

Fonte: Dados da pesquisa (2020).

Corroborando com as ideias de Júlio e Neto (2002), no qual as equipes autogerenciáveis podem ser muito úteis em gerar maior autonomia aos colaboradores que podem demonstrar e aplicar suas qualidades potencializadas, desenvolvendo o melhor de cada colaborador, na flexibilidade em tomar decisões, facilidade e dinamismo da adaptação, bom convívio entre pessoas das mais diversas gerações, rapidez na ações, agilidade no trabalho, diversidade nas habilidades constroem uma equipe mais equilibrada e, consequentemente, mais consolidada nas atribuições.

Ao serem questionados sobre as dificuldades comportamentais existentes dentro da equipe, atrapalhando no bom desempenho, a Tabela 10 pontua que 62,5\% afirmam ser a falta de disciplina, os outros 37,5\% responderam que é a falta de flexibilidade por parte dos colegas de equipe.

Tabela 10: Dificuldades comportamentais que atrapalham no desempenho da equipe.

\begin{tabular}{lcc}
\hline Variáveis & $\begin{array}{c}\text { Referência } \\
\text { Absoluta }\end{array}$ & $\begin{array}{c}\text { Referência } \\
\text { Relativa }\end{array}$ \\
\hline Falta de Disciplina & 5 & $62,5 \%$ \\
\hline Falta de Flexibilidade & 3 & $37,5 \%$ \\
\hline Total & $\mathbf{8}$ & $\mathbf{1 0 0 \%}$ \\
\hline
\end{tabular}

Fonte: Dados da pesquisa (2020).

Um método de treinamento das organizações no envolvimento de todos em um compromisso maior pode instigar em todos uma colaboração maior com as funções a serem executadas, sobressaindo-se as limitações individuais de cada (Júlio \& Neto, 2002).

Quanto aos colaboradores da equipe que enxergam a dificuldade na atuação dentro da organização, 37,5\% responderam que se deve à resistência por partes dos demais setores da empresa, outros 37,5\% responderam ser a tomada de decisão em equipe, enquanto $25 \%$ dos entrevistados diz ser a falta da liderança, dados este presentes na Tabela 11 .

Tabela 11: Dificuldades na atuação da equipe..

\begin{tabular}{lcc}
\hline Variáveis & $\begin{array}{c}\text { Referência } \\
\text { Absoluta }\end{array}$ & $\begin{array}{c}\text { Referência } \\
\text { Relativa }\end{array}$ \\
\hline Resistência dos demais setores & 3 & $37,5 \%$ \\
\hline Tomada de decisão em equipe & 3 & $37,5 \%$ \\
\hline Falta da Liderança & 2 & $25 \%$ \\
\hline Total & 8 & $100 \%$ \\
\hline
\end{tabular}


Dar autonomia suficiente ao colaborador é fundamental para as organizações, já não existe mais espaço para empresas extremamente burocráticas, no qual um vê o problema, comunica-se para outro e assim continua até chegar a quem tem o conhecimento e poder, a autoridade para resolver; no mercado do futuro é preciso ser mais flexível, dinâmico, saber se comunicar, interagir, tomar decisões, deixando as inseguranças de lado, isto é uma questão de sobrevivência (Marras, 2011).

Um fato que pode surgir com a implantação de uma equipe autogerenciável é o medo dos gestores perderem o poder total, isto não acontece no contexto real, apenas desempenharam um novo papel na organização: o de norteador da missão, na busca de obter melhorias e crescimento (Wellins, Byham \& Wilson, 1994).

Na Tabela 12 descreve com relação ao trabalho em equipe, $75 \%$ dos entrevistados responderam que sabem conduzir os trabalhos em equipe, e 25\% disseram que não, nem todos os membros sabem trabalhar em equipe.

Tabela 12: Desempenho na condução do trabalho em equipe.

\begin{tabular}{lcc}
\hline Variáveis & $\begin{array}{c}\text { Referência } \\
\text { Absoluta }\end{array}$ & $\begin{array}{c}\text { Referência } \\
\text { Relativa }\end{array}$ \\
\hline SIM & 6 & $75 \%$ \\
\hline NÃO & 2 & $25 \%$ \\
\hline Total & $\mathbf{8}$ & $\mathbf{1 0 0 \%}$ \\
\hline
\end{tabular}

Fonte: Dados da pesquisa (2020).

Uma das maiores vantagens no modelo de equipes autônomas é o grau de envolvimento do colaborador com o trabalho e com o comprometimento na organização, isto é, saber trabalhar em equipe, desempenhando suas funções na coletividade, lidar com os conflitos e situações nos mais vários níveis também faz parte de estar em uma equipe autônoma, principalmente nas relações em conjunto para melhor desempenhar o papel que lhes foi imposto, e que sabemos não ser caminhos fáceis e que os ideais nem sempre serão coesos e harmoniosos (Robbins, 2005).

Sobre as conquistas da equipe, $100 \%$ dos participantes da pesquisa responderam que o desempenho de todos trouxe resultados satisfatórios para a empresa, isto está representado na tabela13, e que se reflete em toda a equipe, parcerias fechadas com empresas no exterior, com abertura do negócio fora do país e os softwares de processos seletivos internos totalmente via internet, proporcionaram o alcance das metas organizacionais, a abertura de uma filial no exterior e a satisfação de todos.

Tabela 13: Resultado da equipe auto gerenciável.

\begin{tabular}{lcc}
\hline Variáveis & $\begin{array}{c}\text { Referência } \\
\text { Absoluta }\end{array}$ & $\begin{array}{c}\text { Referência } \\
\text { Relativa }\end{array}$ \\
\hline Positivo & 8 & $100 \%$ \\
\hline Negativo & - & - \\
\hline Total & $\mathbf{8}$ & $\mathbf{1 0 0 \%}$ \\
\hline
\end{tabular}

Fonte: Dados da pesquisa (2020).

Grandes empresas no mundo têm buscado criar e desenvolver equipes autogerenciáveis para aumentar sua produtividade e melhorar os resultados, porém precisar atuar com foco e determinação, para que não fique em sonhos frustrados (Robbins, 2005). 
As empresas que melhor se adaptaram na modalidade de equipes autogerenciáveis são aquelas que buscam incentivar o colaborador a trabalhar na coletividade pela qualidade e liberdade na atuação, e não pelo tempo ou serviço proposto no contrato (Jubram, 2012).

Quanto ao grau de dificuldade das conquistas, a Tabela 14 apresenta que 100\% dos entrevistados afirmaram a responsabilidade e compromisso com os processos empresariais nas tomadas de decisão, no sentido de obter um resultado excelente, traz uma dificuldade bem maior. Na empresa em questão conseguir fechar contratos de trabalho com empresas clientes do exterior foi um grande avanço, criar um plano de ação para conquistar a confiança dessas empresas foi um grande desafio.

Tabela 14: Grau de dificuldade nas conquistas.

\begin{tabular}{lcc}
\hline Variáveis & $\begin{array}{c}\text { Referência } \\
\text { Absoluta }\end{array}$ & $\begin{array}{c}\text { Referência } \\
\text { Relativa }\end{array}$ \\
\hline SIM & 8 & $100 \%$ \\
\hline NÃO & - & - \\
\hline Total & $\mathbf{8}$ & $\mathbf{1 0 0 \%}$ \\
\hline
\end{tabular}

Fonte: Dados da pesquisa (2020).

Outro desafio enfrentado para o gestor é a função de coach, principalmente existe um trabalho contínuo do modelo de equipes autônomas, nesta nova habilidade de que o gestor deve ajudar os colaboradores a direcionar seus esforços, empoderarse dos pontos fortes e aprimorar os pontos fracos, e, acima de tudo, orientar os que em um futuro breve farão parte da equipe (Vecchio, 2009).

\section{Conclusão}

Esta pesquisa teve como objetivo mostrar as conquistas e desafios que equipes autogerenciáveis têm no contexto atual das organizações, e o diferencial que podem trazer para as mesmas no mercado competitivo em que estão inseridas.

A pesquisa revelou que, apesar da autonomia que as equipes possuem, para que estas desenvolvam suas atividades no ambiente em que estão inseridas, não depende somente da organização e/ou do líder, mas também dos componentes da equipe, de como cada indivíduo enxerga o ambiente e desenvolve suas competências na atuação das atividades laborais.

Equipes autônomas enfrentam diversas dificuldades no espaço laboral. Na compilação dos dados observou-se que foi possível descobrir algumas dessas dificuldades, resistência como: outros departamentos que não contribuem com a execução das atribuições, por inflexibilidade ao processo; a própria equipe por dificuldades no pertencimento da gestão participativa, no qual todos assumem a função do líder na tomada de decisão; e a dificuldade na alta cúpula da organização com o receio de delegar poder suficiente à equipe para agir. Sendo estes fatores que influenciam na eficácia do desempenho de uma equipe autogerenciável.

Contrapondo-se aos diversos desafios enfrentados, têm-se as inúmeras conquistas da equipe, que dependem de fatores da contribuição tanto internamente quanto externamente do mercado, porém de resultados surpreendentes aos objetivos organizacionais. No caso da pesquisa, as conquistas vieram com o fechamento de contrato com empresas no exterior e a abertura de uma filial também no exterior, na expansão do mercado e desenvolvimento das atividades.

Finaliza-se esta pesquisa sugerindo que estudos futuros explorem maneiras como o Treinamento \& desenvolvimento atuando de forma sistema e continua podem contribuir na minimização das dificuldades vislumbradas em equipes autogerenciadas, no intuito do crescimento na gestão do empreendimento. 


\section{Referências}

Blanchard, Kenneth, H., et al (1996). Empowerment exige mais que um minuto. Objetiva.

Cury, A. (1991). Organização \& Métodos. Perspectiva comportamental \& abordagem contingencial. Atlas.

Cardozo, E. (2012). Mapeamento Sistemático sobre o uso do Autogerenciamento em Equipes de Desenvolvimento de Software. Pós- Graduação em Ciência da Computação. Centro de Informática. Universidade Federal de Pernambuco. Dissertação de Mestrado. < https://repositorio.ufpe.br/handle/123456789/10540>

Cassemiro, C. R., Cardoso, Á. A. \& Chaves, C. (2008). Células Autogeridas: Uma mudança de paradigma. Artigo Científico. Simpósio de Excelência em Gestão e Tecnologia, Associação Educacional Dom Bosco.

Charlwood, A. \& Terry, M. (2007). 21st-Century Models of Employee Representation: structures, processes and outcomes. Industrial Relations Journal, 38, $320-337$.

Chiavenato, I. (2006). Princípios da administração: o essencial em teoria geral da administração. Editora Elsevier.

Davis, K., \& Newstrom, J. W. (1992). Comportamento humano no trabalho. Livraria Pioneira.

Ferreira, M. L. C. B. \& Siqueira, M. M. M. (2005). Antecedentes de intenção da rotatividade: estudo de um modelo psicossocial. Dissertação (Mestrado) Universidade Metodista de São Paulo, SP. file:///D:/Downloads/1252-2212-1-PB.pdf

Gama, M. X. B., et al (2016). A Liderança na Era da Informação e do Conhecimento nas empresas. Pesquisa, Sociedade e Desenvolvimento, 3 (1), 0218. https://doi.org/10.17648/rsd-v3i1.37

Hitchcock, D. \& Willard, M. (1995). Why teams can fail and what to do about it: Essential tools for anyone implementing self-directed work teams. Chicago: Irwin.

Instituto Brasileiro de Geografia e Estatistica, (2017). Projeção da População do Brasil e das Unidades da Federação

< https://www.ibge.gov.br/apps/populacao/projecao/index.html?utm_source=portal\&utm_medium=popclock\&utm_campaign=novo_popclock>.

Jubram, R. (2012). Autonomia $360^{\circ}$ - Saberes aplicáveis a liderança atual. DVS Editora.

Júlio, C. A., \& Neto, J. S. (1998). Liderança e gestão de pessoas: autores e conceitos imprescindíveis. Publifolha, 2002. Goodman e Hudson.

Kinicki, Â. \& Kreitner, R. (2006). Comportamento organizacional, MCGraw-Hill.

Kouzes, J., \& Posner, B. (1997). O desafio da liderança. Campos.

Meffe, C. H. (2006). Implementação de equipes auto gerenciáveis em empresa do setor automotivo: um estudo de caso. Mestrado em Engenharia de Produção Universidade Metodista de Piracicaba - UNIMEP Santa Bárbara D’Oeste. <http://iepapp.unimep.br/biblioteca_digital/pdfs/2006/YMRTFYGECXQP.pdf>

Manz, C. C. \& Sims, H. P. JR. (1996). Empresas sem chefes. Makron Books.

Marras, J. P. (2011). Gestão de pessoas em empresas inovadoras. Saraiva.

Martins, P. H., et al (2017). Contribuições das Comunidades de Prática para o Treinamento e Desenvolvimento de Pessoa. Pesquisa, Sociedade e Desenvolvimento, 4 (4), 239-250. https://doi.org/10.17648/rsd-v4i4.7

Robbins, S. P. (2000). Administração, mudanças e perspectivas. Saraiva.

Robbins, S. P. (2005). Comportamento Organizacional. (11a ed.) Prentice Hall.

Slack, N. et al (1997). Administração da Produção. Atlas, Parente, Cristina A.

Soto, E. (2008). Comportamento organizacional - O impacto das emoções. Cengage Learning.

Vecchio, R. P. (2009). Comportamento Organizacional - Conceitos Básicos. Cengage Leaning.

Vergara, S. C. (2008). Projetos de pesquisa em Administração. (3a ed.) Atlas.

Wellins, R. S. et al (1994). Equipes Zapp! Empowered Teams: Criando energização através de equipes auto gerenciáveis para aumentar a qualidade, produtividade e participação. Campos.

Yin, R. K. (2001). Estudo de caso: planejamento e métodos. Tradução de Daniel Grassi. (2a ed.) Bookman. 